\title{
Nanoscale Evaluation of Strength and Deformation Properties of Ultrahigh-Purity Aluminum*1
}

\author{
Masashi Yoshida ${ }^{1, * 2}$, Tsunetaka Sumomogi ${ }^{2}$, Toshiro Endo ${ }^{2}$, \\ Hiroshi Maeta ${ }^{2}$ and Takao Kino ${ }^{2}$ \\ ${ }^{1}$ Graduate School of Engineering, Hiroshima Kokusai Gakuin University, Hiroshima 739-0321, Japan \\ ${ }^{2}$ Faculty of Engineering, Hiroshima Kokusai Gakuin University, Hiroshima 739-0321, Japan
}

\begin{abstract}
In order to investigate the strength and the deformation properties of metals in nearly perfect crystals, the nanoindentation test is performed on aluminum samples with various purities: $99.9999 \%(6 \mathrm{~N}), 99.99 \%(4 \mathrm{~N})$ and $99 \%(2 \mathrm{~N})$. It is widely known that the strength decreases with increasing purity of metals. On the nanoscale, however, the strength has been revealed to be close to the ideal shear strength, because a nanoscale area is expected to behave as a perfect crystal. In this study, a nanoindentation system that is able to provide indentation load vs penetration depth curves is employed. The experiment is performed on ultrahigh-purity aluminum (99.9999\%), and high-purity aluminum (99.99\%) and commercial-purity aluminum (99\%) so as to discuss the relationship between the purity level and the mechanical properties at room temperature. It is revealed that the penetration depth decreases with increasing purity, and the critical shear stress estimated from the experimental results is close to the ideal shear strength. These results suggest that a perfect crystal is harder than an imperfect crystal. Furthermore, the indentation load vs penetration depth curves indicate a discontinuous deformation of the metals. It is considered that these discontinuities are caused by the existence of impurities or the initiation and the multiplication of dislocations in these samples. [doi:10.2320/matertrans.48.1]
\end{abstract}

(Received September 20, 2006; Accepted October 23, 2006; Published December 25, 2006)

Keywords: ultrahigh-purity aluminum, nanoindentation, perfect crystal, ideal shear strength, discontinuous deformation, purity dependence

\section{Introduction}

Studies on nanoindentation have been progressing, and many reports have been published worldwide. ${ }^{1,2)}$ These reports indicate that nanoindentation can be used to estimate the mechanical properties of materials on a microscopic scale. Furthermore, the experimental findings that the hardness of pure metal increases with the decrease of indentation depth have been reported for single crystals of $\mathrm{Au}, \mathrm{Ag}$ and $\mathrm{Al}^{2-6)}$ This behavior is explained as being a result of the nearly perfect crystalline state in the area of indentation, whereby the mechanical strength approaches the theoretical value. Deformation behavior during indentation has been discussed from the viewpoint of dislocations, and it has been clarified that the deformation behavior on the microscopic scale is different from that on the macroscopic scale. ${ }^{2,4,6-8)}$ However, the materials used in those studies are $99.99 \%$ pure crystals, so the effect of impurity cannot be neglected, and it is difficult to show the strength or the deformation behavior in the state of a perfect metallic crystal.

In the previous report, ${ }^{9)}$ the relationship between the purity and the mechanical properties was investigated using $99 \%$ $(2 \mathrm{~N}), 99.99 \%(4 \mathrm{~N})$ and $99.9999 \%(6 \mathrm{~N})$ aluminum. Furthermore, nanoindentation data was also compared with the results of a conventional tension and hardness test. These results highlighted the differences between microscopicscale and macroscopic-scale properties. The tensile strength and the hardness of $4 \mathrm{~N}$ and $6 \mathrm{~N}$ aluminum were less than those of $2 \mathrm{~N}$ aluminum. However, in the nanoindentation test, the penetration depths for $6 \mathrm{~N}$ and $4 \mathrm{~N}$ aluminum were less than that for $2 \mathrm{~N}$ aluminum. This means that high-purity aluminums $(4 \mathrm{~N}$ and $6 \mathrm{~N})$ are harder than the commercial-

\footnotetext{
${ }^{* 1}$ This paper was Originally Published in J. Japan Inst. Metals 70 (2006) 735-740.

${ }^{* 2}$ Graduate Student, Hiroshima Kokusai Gakuin University
}

purity aluminum $(2 \mathrm{~N})$. The distribution of impurities in the volume of the indentation mark was estimated, and the average number of impurities in the indented volume was about 0 or 1 for $6 \mathrm{~N}$ aluminum. The results suggested that the high-purity aluminum was harder than the commercial-purity aluminum on the microscopic scale. Furthermore, the penetration depth and the indentation mark were investigated, and it was recognized that the penetration depth for $6 \mathrm{~N}$ aluminum decreases with time after nanoindentation.

In this study, to investigate the strength and the deformation behavior of ultrahigh-purity aluminum on the microscopic scale, the nanoindentation test is performed on an ideally perfect crystal using a tester that can provide indentation load versus penetration depth curves. The results are compared with the previous nanoindentation data, ${ }^{9)}$ and the strength and the deformation behavior of ultrahigh-purity aluminum on the microscopic scale are elucidated.

\section{Experimental Procedures}

\subsection{Sample S) $^{9}$}

The starting material used in this work is $99.999 \%(5 \mathrm{~N})$ pure aluminum with a residual resistance ratio of about 5000 in bulk produced by Sumitomo Chemical Co., Ltd. This material is refined by repeating zone melting, and the residual resistance ratio is improved to about 30000 . This material is denoted as the ultrahigh-purity aluminum $99.9999 \%$ (6N) sample, hereafter. In order to clarify the purity dependence of the mechanical properties of aluminum, commercial-purity aluminum of $99 \%(2 \mathrm{~N})$ and high-purity aluminum of $99.99 \%$ $(4 \mathrm{~N})$ are used in addition to the ultrahigh-purity aluminum of $99.9999 \%(6 \mathrm{~N})$. The sample size is $10 \mathrm{~mm} \times 10 \mathrm{~mm} \times$ $1 \mathrm{~mm}$. All samples are electropolished and annealed at $500^{\circ} \mathrm{C}$ for 5 hours in a vacuum of $2 \times 10^{-5} \mathrm{~Pa}$. Furthermore, $6 \mathrm{~N}$ and $4 \mathrm{~N}$ samples are cyclically annealed between $90^{\circ} \mathrm{C}$ and $300^{\circ} \mathrm{C}$ 8 times in a vacuum of $2 \times 10^{-5} \mathrm{~Pa}$. 
To estimate the dislocation density, these samples are etched in a solution of $\mathrm{HCl}+\mathrm{HNO}_{3}$, and the etched samples are observed using a scanning electron microscope. The dislocation density is about $1 \times 10^{7} \mathrm{~m}^{-2}$ in the surface of the $6 \mathrm{~N}$ sample and about $1 \times 10^{9} \mathrm{~m}^{-2}$ in the surface of the $4 \mathrm{~N}$ sample. In the $2 \mathrm{~N}$ sample, the etch pit becomes unclear due to overall corrosion, but it is inferred that the dislocation density of the $2 \mathrm{~N}$ sample is fairly higher than those of the $4 \mathrm{~N}$ and $6 \mathrm{~N}$ samples.

\subsection{Test region}

From the dislocation density described above, the space between dislocations is estimated. The average space between dislocations is about $300 \mu \mathrm{m}$ in the $6 \mathrm{~N}$ sample and about $30 \mu \mathrm{m}$ in the $4 \mathrm{~N}$ sample. That in the $2 \mathrm{~N}$ sample is considered to be several micrometers. The distribution of impurities in the volume of the indentation mark can be estimated from the side length and the penetration depth of the indentation mark. The average number of impurities in the indented volumes at the maximum indentation load are about 0 or 1 for the $6 \mathrm{~N}$ sample, about 25 for the $4 \mathrm{~N}$ sample and about 24000 for the $2 \mathrm{~N}$ sample. ${ }^{9)}$ In the $6 \mathrm{~N}$ sample, no dislocations and no impurity atoms exist in the test region subjected to nanoindentation. Therefore, the test region of nanoindentation in the $6 \mathrm{~N}$ sample is considered to be a nearly perfect crystal. In the $4 \mathrm{~N}$ sample, initial dislocations are rare, but impurities exist in the test region. In the $2 \mathrm{~N}$ sample, the great number of initial dislocations and impurities affect the strength and deformation behaviors. It is considered that mechanical properties of a perfect crystal can be elucidated by performing nanoindentation tests on ultrahigh-purity aluminum.

\subsection{Nanoindentation test}

The instrument used in the present work is the NanoScope III system, which is a scanning probe microscope (SPM) with a nanoindentation function made by Digital Instrument Inc. The Hysitron TriboScope system is attached to the SPM. With this instrument, the details of the sample surface are examined at a nanometer resolution, and the indentation is measured at an accuracy of one nanometer. The instrument can be used to obtain indentation load versus penetration depth curves, as shown in Fig. 1. A triangular pyramid indenter with an apex angle of 90 degrees is employed, which has a tip radius of $75 \mathrm{~nm}$. This radius is mentioned in the specification of the tip, and is confirmed by an empirical method using the relationship between maximum indentation load and penetration depth on fused silica.

The surface state of the sample is carefully examined with the SPM in order to verify the flatness before the nanoindentation test. The peak-to-valley roughness of the sample surface is less than $3 \mathrm{~nm}$ over the observation area of $2 \times$ $2 \mu \mathrm{m}^{2}-3 \times 3 \mu \mathrm{m}^{2}$. The maximum indentation load is in the range of $50 \mu \mathrm{N}$ to $80 \mu \mathrm{N}$. The indentation speed is $4 \mu \mathrm{N} \cdot \mathrm{s}^{-1}$, and the dwell time at the selected maximum load is $0 \mathrm{~s}$ for each indentation. The sample is indented at least 7-10 times. Each indented point is separated from the others by a distance of more than five times the size of the indented mark so as to avoid the influence of the previous indentation.

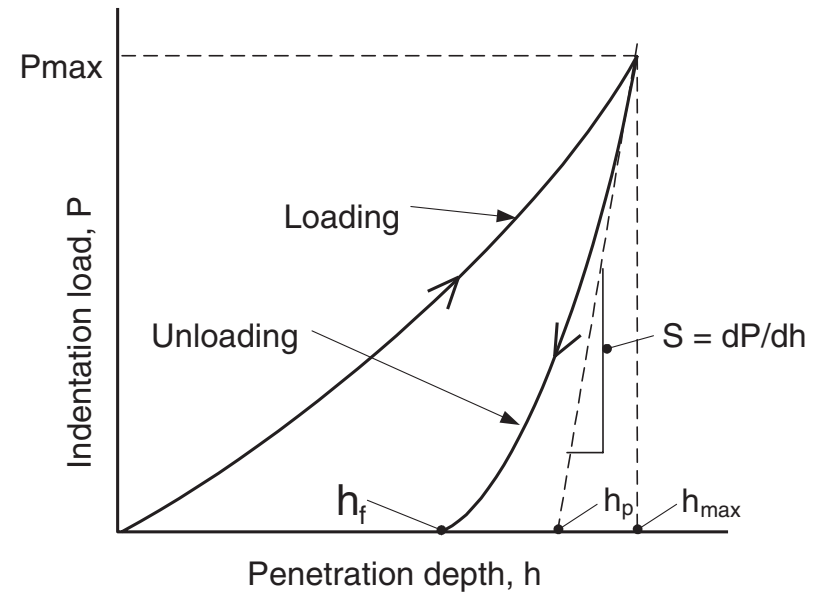

Fig. 1 Indentation load vs penetration depth curve in nanoindentation.

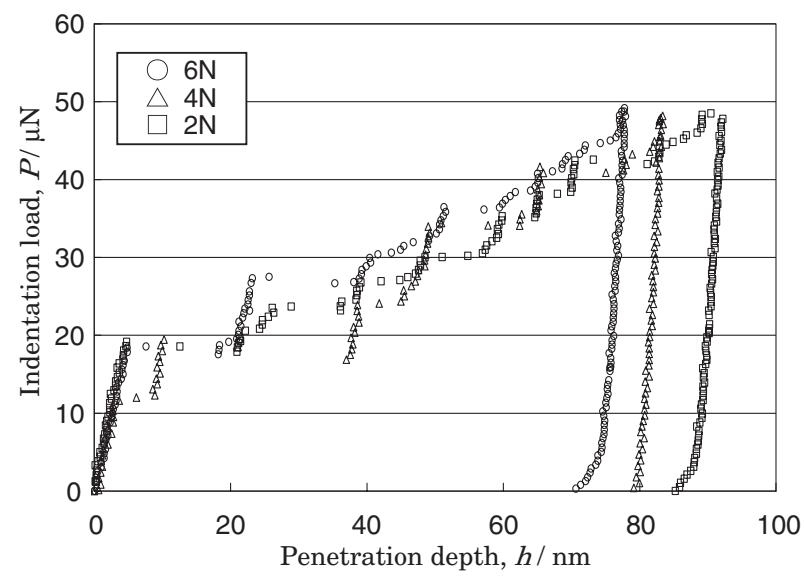

Fig. 2 The indentation load vs penetration depth curves for indentation into aluminum of various purities.

\section{Experimental Results}

\subsection{Strength on microscopic scale}

Figure 2 shows an example of the indentation load versus penetration depth for indentation, where the maximum indentation load is $50 \mu \mathrm{N}$. Both the total penetration depths at the maximum indentation load and the penetration depths of residual impressions for $6 \mathrm{~N}$ and $4 \mathrm{~N}$ samples are less than those for the $2 \mathrm{~N}$ sample. This result is consistent with the result reported in the previous paper. ${ }^{9)}$ Figure 3 shows the relationship between the total penetration depth and the purity at each indentation load; the penetration depth decreases with increasing purity, that is, the high-purity aluminums, $4 \mathrm{~N}$ and $6 \mathrm{~N}$ samples, show higher strength than that of commercial-purity aluminum, $2 \mathrm{~N}$ sample. These experimental results are explainable in terms of the perfectness of the crystal under the indenter in high-purity aluminum.

\subsection{Deformation behavior on microscopic scale}

We focus on the deformation behavior in the initial stage of deformation. The penetration depth increases suddenly at about $10-20 \mu \mathrm{N}$, as shown in Fig. 2. The indentation load versus penetration depth curve shows discontinuous deformation. This discontinuous deformation has been discussed 


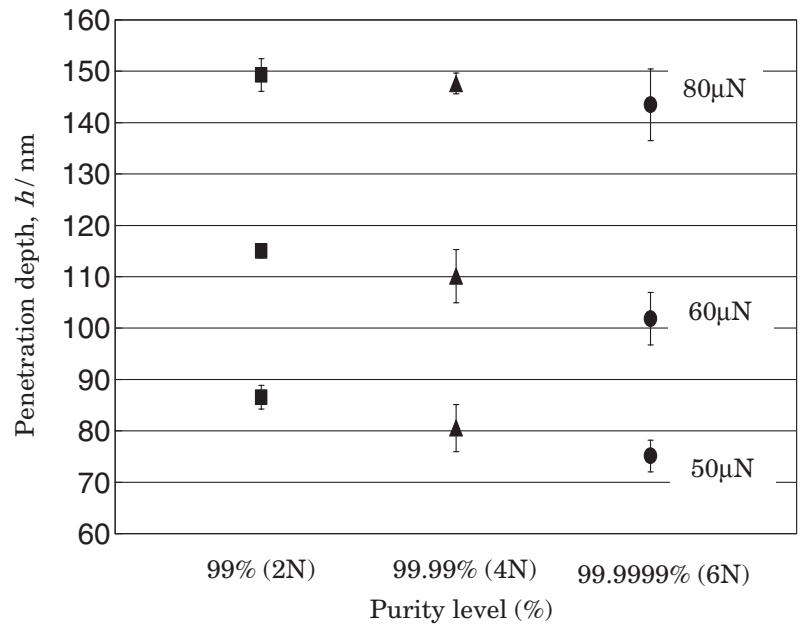

Fig. 3 The relationship between penetration depth and purities at each indentation load.

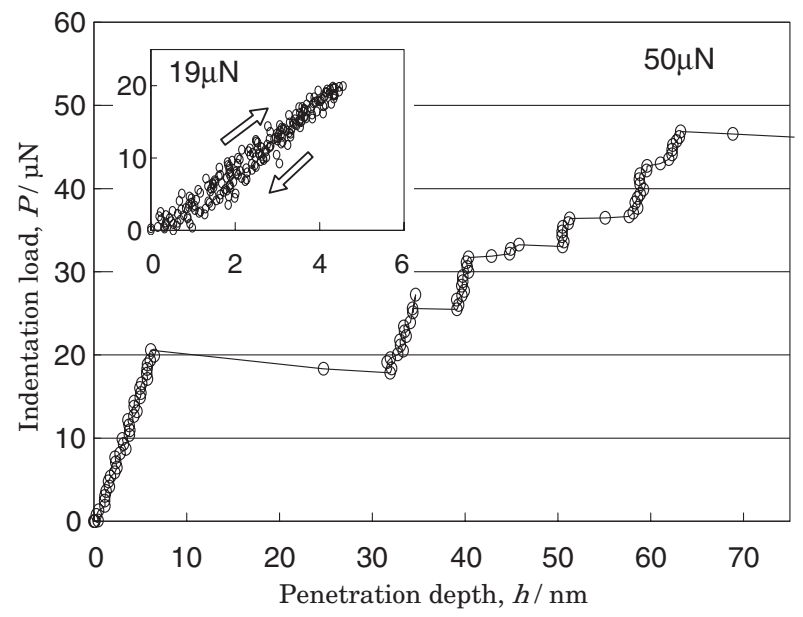

Fig. 4 Deformation behavior induced by nanoindentation on the $6 \mathrm{~N}$ sample.

in terms of the oxide film ${ }^{10)}$ or some unknown contamination layer on the sample surface, ${ }^{3)}$ and the nucleation and emission of dislocations, ${ }^{2,4,6,7)}$ but the mechanism on the microscopic scale is unresolved.

Examples of the indentation load versus penetration depth curve for the $6 \mathrm{~N}$ sample are shown in Fig. 4. In the curve of the maximum load of $50 \mu \mathrm{N}$, the penetration depth suddenly increases to $30 \mathrm{~nm}$ at $20 \mu \mathrm{N}$. A similar phenomenon, namely, indentation burst, has been reported by several researchers, and it is considered to correspond to the initiation of plastic deformation, namely, the yield point. ${ }^{2,3,6,7)}$ In the case of the maximum load of $19 \mu \mathrm{N}$ (inset of Fig. 4), the loading curve and the unloading curve nearly coincide. Furthermore, the indentation mark is not observed after the indenter is removed. From these results, the deformation before the indentation burst at $20 \mu \mathrm{N}$ is considered to be elastic and the subsequent deformation is considered to be plastic.

\section{Discussion}

\subsection{Yield stress}

From the results in Fig. 4, the initial penetration depth

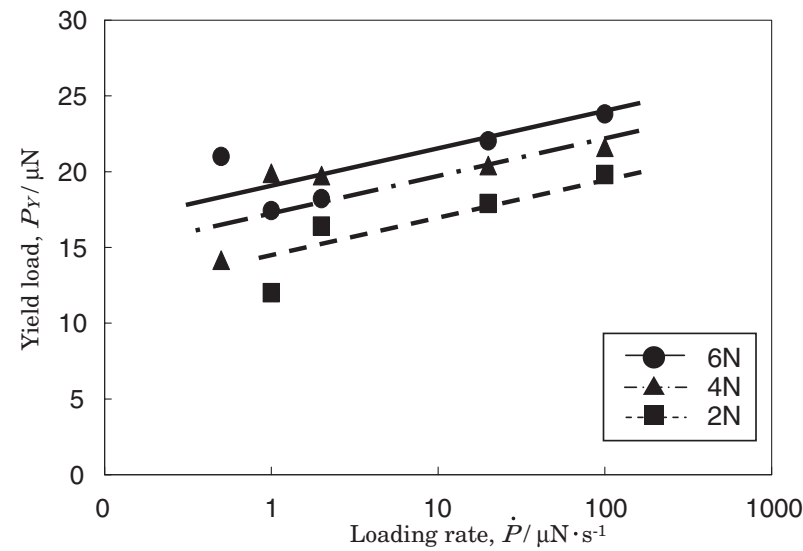

Fig. 5 The yield load $P_{Y}$ vs loading rate $\dot{P}$ for aluminum of various purities.

burst is regarded to be a yielding behavior. Figure 5 shows relationship between the yield load and the loading rate for aluminum of various purities. Each plot is the average of more than five measurements, because the measured yield load scattered considerably. The yield loads of $4 \mathrm{~N}$ and $6 \mathrm{~N}$ samples are higher than that of the $2 \mathrm{~N}$ sample. Since the initial space between dislocations in well-annealed $4 \mathrm{~N}$ and $6 \mathrm{~N}$ samples is about $30 \mu \mathrm{m}$ and $300 \mu \mathrm{m}$, respectively, the test region under the indenter is considered to be a perfect crystal. Therefore, high stress is necessary to create a dislocation. This is why the high-purity aluminum has higher strength than that of commercial-purity aluminum on the microscopic scale. The loading rate has an influence on the yield load for all aluminum samples, and the yield load increases with increasing loading rate. Similar behaviors have been reported by Schuh and Lund ${ }^{11)}$ and Moody et al.. ${ }^{12)}$ This behavior is considered to be the effect of thermal activation or pile-up height around the indentation mark, but it must be examined in more detail.

The average values of the yield load for all aluminum samples are $21 \mu \mathrm{N}$ for $6 \mathrm{~N}, 19 \mu \mathrm{N}$ for $4 \mathrm{~N}$ and $17 \mu \mathrm{N}$ for $2 \mathrm{~N}$. Using these yield loads, let us calculate the maximum shear stress of aluminum samples. The indenter contacts with the sample elastically under a load smaller than the yield load, so the maximum shear stress is calculated on the basis of Heltzian theory. ${ }^{13)}$

$$
P_{m}=\left(\frac{6 P_{Y} E^{* 2}}{\pi^{3} R^{2}}\right)^{1 / 3}
$$

Here, $P_{Y}$ is the yield load and $R$ is the tip radius. In this study, the tip radius is $75 \mathrm{~nm}$. The reduced modulus $E^{*}$ comprises the moduli of the indenter and the specimen, and is given by ${ }^{13)}$

$$
E^{*}=\left[\frac{\left(1-v_{s}^{2}\right)}{E_{s}}+\frac{\left(1-v_{i}^{2}\right)}{E_{i}}\right]^{-1},
$$

where $E_{i}$ and $E_{s}$ are the elastic moduli of the indenter and the sample, respectively. $v_{i}$ and $v_{s}$ are Poisson's ratios for the indenter and the sample, respectively. The value of $E^{*}$ is calculated as $71 \mathrm{GPa}$ from eq. (2), using $E_{i}=1000 \mathrm{GPa}$, $E_{s}=70 \mathrm{GPa}, v_{i}=0.07$ and $v_{s}=0.3$ for the indenter and the aluminum sample, respectively. ${ }^{14)}$ 
Table 1 Experimental values of yield load and the estimated critical shear stress for various purity aluminum.

\begin{tabular}{ccc}
\hline & $\begin{array}{c}\text { Yield load } \\
P_{Y} / \mu \mathrm{N}\end{array}$ & $\begin{array}{c}\text { Estimated critical shear } \\
\text { stress } \tau_{\max } / \mathrm{GPa}\end{array}$ \\
\hline $6 \mathrm{~N}$ & 21 & 4.8 \\
$4 \mathrm{~N}$ & 19 & 4.6 \\
$2 \mathrm{~N}$ & 17 & 4.4 \\
\hline
\end{tabular}

The maximum shear stress $\tau_{\max }$ is given by ${ }^{13}$

$$
\tau_{\max }=0.31 P_{m} .
$$

The estimated yield load $P_{Y}$ and the maximum shear stress $\tau_{\max }$ are shown in Table 1 . The estimated maximum shear stress is in the range of $4.4-4.8 \mathrm{GPa}$. This maximum shear stress on the microscopic scale is higher value than that, $2 \times 10^{-3}-2 \times 10^{-2} \mathrm{GPa},{ }^{15)}$ obtained by the tensile test on the macroscopic scale. The maximum shear stress $\tau_{\max }$ calculated from the shear modulus $\mu$ is $4.2 \mathrm{GPa}$, using $\mu / 2 \pi$. This value is on the same order as that estimated from yield load $P_{Y}$. The estimated maximum shear stress increases with increasing purity. It is assumed that the microscopic properties differ markedly from macroscopic ones. The initial penetration depth burst occurs when the maximum shear stress reaches the critical shear stress. In addition, the point at which the maximum shear stress is induced is a certain distance $\mathrm{z}$ from the contact point of the indenter. The distance $z$ is estimated from the distribution of stress induced in a semi-infinite body, and is expressed as ${ }^{13}$ )

$$
z=0.47 a,
$$

where the radius of the circle of contact $a$ is given by ${ }^{13)}$

$$
a=\sqrt[3]{\frac{3}{2} \frac{P R}{E^{*}}}
$$

The distance $z$ from the sample surface beneath the indenter becomes about $10 \mathrm{~nm}$ for all samples, which corresponds to the subsurface region. These results indicate that the yielding behaviors observed in the present nanoindentation are not surface phenomena but behaviors in a bulk material.

In the $6 \mathrm{~N}$ sample, no initial dislocations and no impurities exist in the region subjected to nanoindentation. Therefore, it is considered that the ideal strength is obtained in the nanoindentation of $6 \mathrm{~N}$ aluminum. Moreover, the crystal approaches a more perfect state as the purity increases, so the maximum shear stress increases with increasing purity. The present yielding behavior occurs when the maximum shear stress approaches the ideal strength.

\subsection{Young's modulus}

Young's modulus can be calculated from the unloading curve; this calculation is based on the method established by Oliver and Pharr. ${ }^{16)}$ They determined the area function from only the shape of the indenter. However, the area function leads to error when the indentation is performed for a soft material with a penetration depth of less than $100 \mathrm{~nm} .{ }^{17-20)} \mathrm{It}$ is difficult to determine the ideal area function for an indenter with a complicated shape.

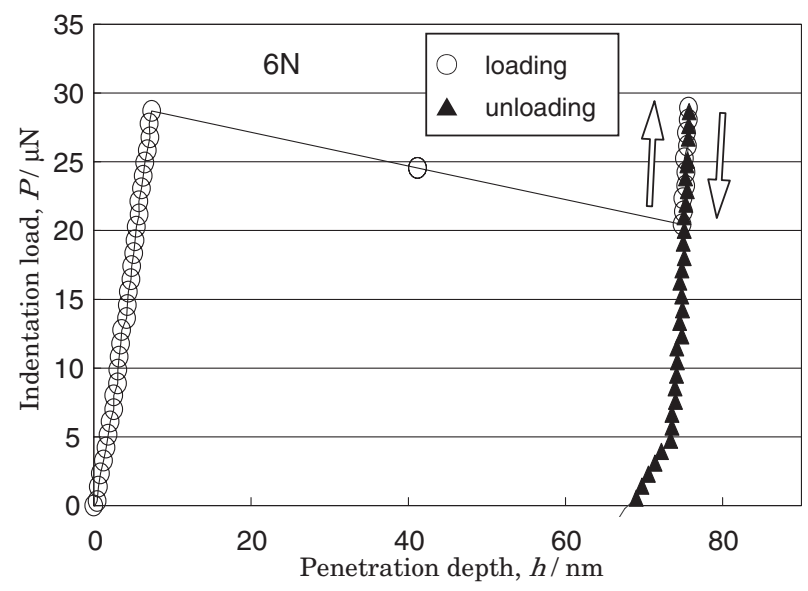

Fig. 6 Indentation load vs penetration depth curve for the $6 \mathrm{~N}$ sample at a maximum indentation load of $30 \mu \mathrm{N}$.

Since the indentation load versus penetration depth curves show elastic loading and unloading prior to the initial penetration depth burst, Young's modulus can be obtained from the slope of the initial loading and unloading curves. Furthermore, it is assumed that the indenter tip is spherical for the analysis in the initial stage. The slope of elastic unloading, for the case of a spherical indenter, is expressed as $^{21)}$

$$
P=\frac{4}{3} E^{*} R^{1 / 2} h^{3 / 2}
$$

The reduced modulus is given by ${ }^{21)}$

$$
E^{*}=\frac{1}{2} \frac{d P}{d h} \frac{\sqrt{\pi}}{\sqrt{A}},
$$

where $d P$ and $d h$ are the quantities of increase for indentation load and penetration depth, respectively. $A$ is the projected area given by

$$
A=\pi a^{2} .
$$

The value of $E_{s}$ is obtained from eq. (2).

Young's moduli obtained from the initial slope shown in Fig. 4 are in the range of $85-90 \mathrm{GPa}$. Young's moduli estimated from the unloading curve at the maximum indentation load were found to increase with increasing purity. ${ }^{22)}$ Young's modulus exhibits a dependence on purity levels. The impurities in the sample lead to lattice relaxation, so it is considered that Young's modulus changes in accordance with purity levels, but this must be examined in the future.

\subsection{Deformation behavior}

The discontinuous deformation during the indentation will now be discussed. Figure 6 shows the indentation load versus the penetration depth curve for the $6 \mathrm{~N}$ sample at the maximum load of $30 \mu \mathrm{N}$. The initial penetration depth burst occurs at an indentation load of about $28 \mu \mathrm{N}$, and it is the initiation of plastic deformation, namely, yielding behavior. The measured values of the yield load scatter considerably, as described in section 4.1 , and the values for the $6 \mathrm{~N}$ sample vary between $15 \mu \mathrm{N}$ and $33 \mu \mathrm{N}$ because of the differences in 


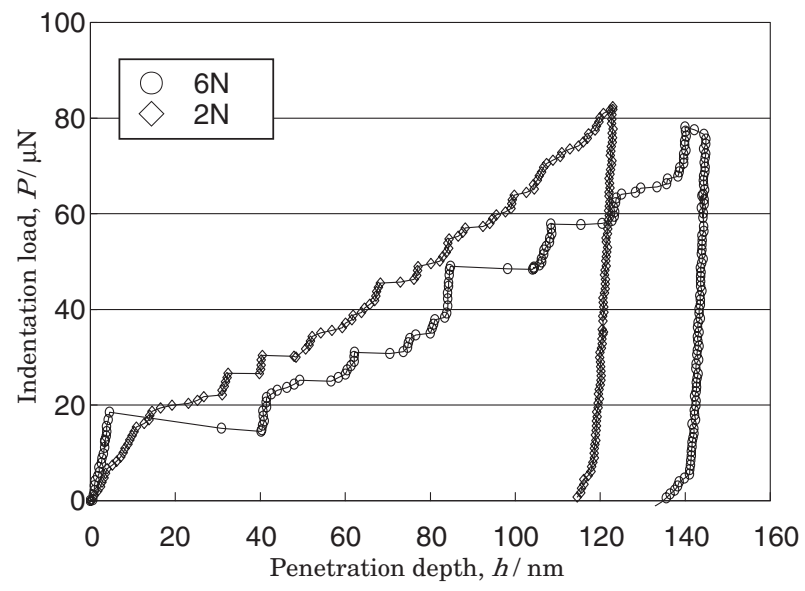

Fig. 7 Indentation load vs penetration depth curves for the $6 \mathrm{~N}$ and the machined $2 \mathrm{~N}$ aluminum.

the contact point. The loading curve after the initial burst coincides with the unloading curve in the load range of 20 $30 \mu \mathrm{N}$. Therefore, the deformation during nanoindentation is considered to be alternating elastic and plastic deformations.

Indentation load versus penetration depth curves for the cyclically annealed $6 \mathrm{~N}$ sample and the machined $2 \mathrm{~N}$ sample are shown in Fig. 7. The $2 \mathrm{~N}$ aluminum sample is face-turned with a single-crystal diamond tool. The machining conditions for the sample are cutting speed of $447 \mathrm{~m} \cdot \mathrm{min}^{-1}$, feed rate of $0.05 \mathrm{~mm} \cdot \mathrm{rev}^{-1}$ and depth of cut of $4 \mu \mathrm{m}$. For the $2 \mathrm{~N}$ sample machined by cutting, penetration depth burst is reduced, and nearly continuous deformation is observed. The penetration depth burst exhibits a dependence on purity level and dislocation density.

The impurities in the sample prevent the movement of dislocations, so the movable distance becomes shorter and the penetration depth burst is reduced. Furthermore, in the machined $2 \mathrm{~N}$ sample, the yield load of $6 \mu \mathrm{N}$ is obtained. The yield load for the $6 \mathrm{~N}$ sample is a higher value, $19 \mu \mathrm{N}$, than that for the machined $2 \mathrm{~N}$ sample. In the ideally perfect crystal, high stress is necessary to create a dislocation. The penetration depth burst occurs when the resolved shear stress becomes closer to the ideal strength. These results suggest that a defect-free region has a high resistance to dislocation nucleation.

\section{Conclusions}

In order to investigate the strength and the deformation behavior of a nearly perfect metal crystal, nanoindentation tests was performed on aluminum samples with various purities: $99.9999 \%(6 \mathrm{~N}), 99.99 \%(4 \mathrm{~N})$ and $99 \%(2 \mathrm{~N})$. The following results were obtained.

(1) To reconfirm the previous experimental results, the relationship between the total penetration depth and the purity at each indentation load was examined, and it was clarified that the penetration depth decreases with increasing purity. This suggested that high-purity aluminum, $4 \mathrm{~N}$ and $6 \mathrm{~N}$, shows higher strength than commercial-purity aluminum, $2 \mathrm{~N}$.

(2) The initial penetration depth burst is the initiation of plastic deformation, namely, a yielding behavior. The maximum shear stress calculated from the yield load is close to the ideal strength of aluminum. Moreover, the calculated maximum shear stress increases with increasing purity. These results indicate that a perfect crystal is harder than an imperfect crystal.

(3) Deformation behavior on the microscopic scale shows discontinuous deformation. Such a deformation behavior is considered to be composed of elastic deformation and plastic deformation.

(4) In the $2 \mathrm{~N}$ sample machined by cutting, penetration depth burst is reduced, and nearly continuous deformations are observed. Deformation behavior on the microscopic scale exhibits a dependence on the purity level and the dislocation density.

\section{Acknowledgements}

The authors wish to thank Mr. Fujii, a member of the technical staff of the Research Institute of Advanced Technology of Hiroshima Kokusai Gakuin University, for fabricating all the samples used in the present study.

\section{REFERENCES}

1) T. Sawa, Y. Akiyama, A. Shimamoto and K. Tanaka: J. Mater. Res. 14 (1999) 2228-2232

2) A. M. Minor, J. W. Morris, Jr. and E. A. Stach: Appl. Phys. Lett. 79 (2001) 1625-1627.

3) S. G. Corcoran, R. J. Colton, E. T. Lilleodden and W. W. Gerberich: Phys. Rev. 55 (1997) 57-60.

4) J. D. Kiely, K. F. Jarausch, J. E. Houston and P. E. Russell: J. Mater. Res. 14 (1999) 2219-2227.

5) G. M. Pharr and W. C. Oliver: J. Mater. Res. 4 (1989) 97-101.

6) A. Gouldstone, H. J. Koh, K. Y. Zeng, A. E. Giannakopoulos and S. Suresh: Acta. Mater. 48 (2000) 2277-2295.

7) T. Ohmura, K. Tsuzaki and F. Yin: Mater. Trans. 46 (2005) 2026-2029.

8) K. J. Van Vliet, J. Li, T. Zhu, S. Yip and S. Suresh: Phys. Rev. B 67 (2003) 104105, 1-15.

9) T. Sumomogi, M. Yoshida, M. Nakamura, H. Osono and T. Kino: Mater. Trans., JIM 46 (2005) 1996-2002.

10) D. E. Kramer, K. B. Yoder and W. W. Gerberich: Philos. Mag A 81 (2001) 2033-2058.

11) C. A. Schuh and A. C. Lund: J. Mater. Res. 19 (2004) 2152-2158.

12) N. R. Moody, A. Strojny, D. Medlin, S. Gurthrie and W. W. Gerberich: Mater. Res. Soc. Symp. Proc. 522 (1998) 281-286.

13) S. P. Timoshenko and J. N. Goodier: Theory of Elasticity Third Edition, (Kosaido, Japan, 1970) 398-402.

14) K. Ebihara: Rikanenpyo, (Chronological Scientific Tables, Japan, 1988) 444.

15) D. A. Didenko and V. V. Pustovalov: J. Low. Temp. Phys. 11 (1973) 65-76.

16) W. C. Oliver and G. M. Pharr: J. Mater. Res. 7 (1992) 1564-1583.

17) J. C. Hay, A. Bolshakov and G. M. Pharr: J. Mater. Res. 14 (1999) 2296-2305.

18) T. Sawa and K. Tanaka: J. Mater. Res. 16 (2001) 3084-3096.

19) F. M. Borodich, L. M. Keer and C. S. Korach: Nanotechnology 14 (2003) 803-808

20) K. W. McElhaney, J. J. Vlassak and W. D. Nix: J. Mater. Res. 13 (1998) 1300-1306.

21) Anthony. C. Fischer-Cripps: Nanoindentation, (Springer, New York, 2002) 40-43.

22) M. Yoshida, T. Sumomogi, T. Endo, H. Maeta and T. Kino: Proceedings of $12^{\text {th }}$ International Conference on Ultra High Purity Base Metals, Nagasaki, Japan, November 7-11 (2005), in press. 